This item was submitted to Loughborough's Research Repository by the author.

Items in Figshare are protected by copyright, with all rights reserved, unless otherwise indicated.

\title{
Multiparameter flow cytometry for the characterisation of extracellular markers on human mesenchymal stem cells
}

PLEASE CITE THE PUBLISHED VERSION

http://dx.doi.org/10.1007/s10529-013-1422-0

\section{PUBLISHER}

(C) Springer Science+Business Media

\section{VERSION}

AM (Accepted Manuscript)

\section{LICENCE}

CC BY-NC-ND 4.0

\section{REPOSITORY RECORD}

Chan, Alexander K.C., Thomas R.J. Heathman, Karen Coopman, and Christopher J. Hewitt. 2014. "Multiparameter Flow Cytometry for the Characterisation of Extracellular Markers on Human Mesenchymal Stem Cells". figshare. https://hdl.handle.net/2134/14884. 
This item was submitted to Loughborough's Institutional Repository (https://dspace.lboro.ac.uk/) by the author and is made available under the following Creative Commons Licence conditions.

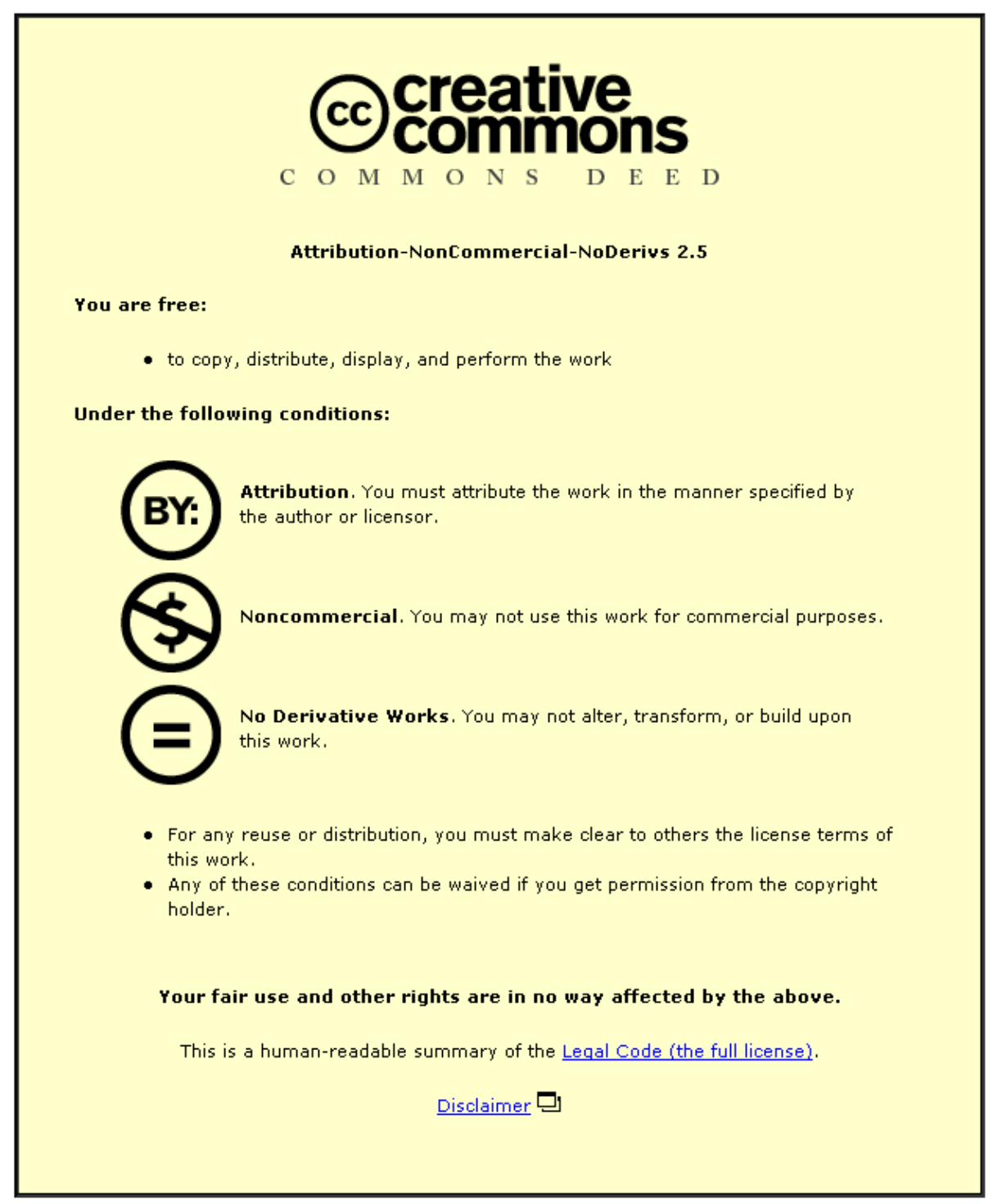

For the full text of this licence, please go to: http://creativecommons.org/licenses/by-nc-nd/2.5/ 
1 Biotechnology Letters - Bioprocessing and Biological engineering

2 Multiparameter flow cytometry for the characterisation of extracellular markers

3 on human mesenchymal stem cells

4 Alexander K. C. Chan ${ }^{1}$, Thomas R. J. Heathman ${ }^{1}$, Karen Coopman ${ }^{1}$, and Christopher J. 5 Hewitt $^{1 *}$

$6{ }^{1}$ Centre for Biological Engineering, Department of Chemical Engineering, Loughborough

7 University, Leicestershire, LE11 3TU, United Kingdom

8 *Corresponding author: Prof. Christopher J. Hewitt (Telephone: +44-1509 222506; Fax: +44-

91509 222506; E-mail: c.j.hewitt@lboro.ac.uk)

\section{Abstract}

13 Extracellular surface proteins can be used to identify fully functional human mesenchymal 14 stem cells (hMSCs) in a mixed population. Here a multiparameter flow cytometry assay was 15 developed in order to examine the expression of several bone marrow-derived hMSC markers 16 simultaneously at the single cell level. The multiparameter approach demonstrates a depth of analysis that goes far beyond the conventional single or dual staining methods. CD73, CD90 and CD105 were chosen as positive markers as they are expressed on multipotent hMSCs,

19 whilst CD34 and HLA-DR were chosen as negative indicators. Single colour analysis suggested a population purity of $100 \%$, in contrast, when analysed via the multiparameter 21 method it was found that the $\mathrm{CD} 73^{+\mathrm{ve}} / \mathrm{CD} 105^{+\mathrm{ve}} / \mathrm{CD} 90^{+\mathrm{ve}} / \mathrm{HLA}-\mathrm{DR} \mathrm{R}^{-\mathrm{ve}} / \mathrm{CD} 34^{-\mathrm{ve}}$ phenotype represented $94.49 \% \pm 1.31 \%$ of the total cell population. Also, CD271 has recently been

23 posited as a definite early stage hMSC marker but here we show it is not present on pre24 passage cells, highlighting the need for careful marker selection. 
26 Keywords: CD271, characterisation, extracellular markers, human mesenchymal stem cells

27 (hMSCs), multiparameter flow cytometry,

\section{Introduction}

Human mesenchymal stem cells (hMSCs), also known as multipotent stromal cells, were first isolated from bone marrow and found to differentiate into adipocytes, chondrocytes and osteoblasts in vitro (Pittenger et al. 1999; Friedenstein et al. 1970). In addition, it is now known that hMSCs secrete multiple anti-inflammatory, angiogenic and immunomodulatory factors that serve to repair locally damaged tissue (Caplan 2007). For these reasons they are becoming a cell type of increasing interest for tissue engineering and regenerative medicine research. Currently there are over 150 active bone marrow-derived mesenchymal stem cell clinical trials with only a handful in phase 3 ; hence there is now a real need for robust product characterisation (http://www.clinicaltrials.gov/).

Mesenchymal stem cells are not unique to bone marrow; they have also been isolated from dental pulp, umbilical cord vein and adipose tissue (Williams and Hare 2011). The varied tissue sources and isolation techniques used raise the issue of whether the resulting cell populations are true hMSCs at all and whether the many published studies conducted are at all comparable (for a comprehensive review see (Rojewski et al. 2008)). Currently there is no single marker that defines an hMSC and therefore investigators will use a combination of markers to characterise a population. To address this concern the International Society for Cellular Therapies (ISCT) has proposed minimal criteria that define a true hMSC (Dominici et al. 2006). These include the ability to adhere to standard tissue culture plastic; differentiation into the adipocytes, chondrocytes and osteoblasts lineages; and expression of 2 
specific surface antigen markers. These surface antigens include expression of CD90, CD73 and CD105; hMSCs must also lack the expression of CD45, CD34, CD14, CD79 $\alpha$ and HLADR as they are indicators of non-stromal cell types. Recently this has been updated to include CD10, CD146 and GD2 as further positive markers (Rasini et al. 2013).

Recently, it has been suggested that another marker, CD271 (Low-Affinity Nerve Growth Factor Receptor), may in fact be specific for the colony-forming-unit-fibroblast (CFU-Fs) found in the stromal region (Jones et al. 2006; Kuci et al. 2010). Previous studies have demonstrated via fluorescent-activated cell sorting (FACS) that by collecting CD271 ${ }^{+v e}$ cells, the resulting population has a greater CFU-F capability when compared to a population of non-sorted cells. However, it is known to be down-regulated over prolonged culture in vitro suggesting it may be an efficient marker to initially select for bone marrow hMSCs but not as a positive phenotypic marker over multiple passages (Harichandan and Buhring 2011).

Flow cytometry is a high-throughput analytical technique that can be used to study protein expression properties of a cell via fluorescently labelled monoclonal antibodies. Most flow cytometers can measure the expression of several antigens provided that a sample is split for analysis using one or two fluorophore-labelled antibodies at a time. While technically straightforward, single or dual staining approaches do not provide the resolution of multiple antigens within the same population. Multiparameter (also known as multicolour) flow cytometry has been applied to clinical diagnostics and immunology, providing the highresolution information needed to identify subtle phenotypic differences with statistical robustness (Peters and Ansari 2011). Unfortunately, multiparameter flow cytometry is not routinely used to define stem cell phenotypes, although a previous study has demonstrated the use of a seven-colour flow cytometry assay to examine the differential expression of markers 3 
between freshly isolated bone marrow and umbilical cord samples (Martins et al. 2009). However, it is envisaged that greater uptake of multiparameter flow cytometry is expected to provide similar benefits to those achieved in the aforementioned fields of research.

Previous work by our laboratory has demonstrated that multiparameter flow cytometry can be used to characterise human embryonic stem cells (Brosnan et al. 2013). Here we show that this technique can be used to monitor five surface antigens that correspond to the hMSC phenotype. CD73, CD90 and CD105 were selected, as they are the most widely accepted surface markers of multipotency, additionally we also examine CD271 as a potential positive marker. CD34 and HLA-DR were selected as negative markers, as they indicate differentiation down the primitive hematopoietic and leukocyte lineages respectively.

Here we demonstrate the power of a relatively simple and cost effective assay using a fivecolour/two laser array for the analysis of extracellular marker expression on hMSCs. The multiparameter approach provides a simple way to determine putative hMSCs from a mixed population and for quality control that can be implemented to further facilitate process development.

3 Materials \& Methods

\section{Cell Culture}

6 Human bone marrow derived mesenchymal stem cells (Lonza, Germany) were obtained from 7 a single healthy donor after the patient provided informed consent. The local Ethical 8 Committee approved the use of the sample for research. hMSCs passage 2-6 were cultured in 9 DMEM supplemented with 10\% (v/v) foetal bovine serum (FBS; Hyclone, Belgium) and 2 
100 mM L-glutamine (Lonza, UK); medium was replaced every 3 days. Cells were maintained in

101 a humidified incubator at $37^{\circ} \mathrm{C}$ in air containing $5 \% \mathrm{v} / \mathrm{v} \mathrm{CO}_{2}$. The cells were passaged every

1026 days using $3 \mathrm{ml} 0.25 \% \mathrm{w} / \mathrm{w}$ trypsin/EDTA (Lonza, UK) for 5 minutes at $37^{\circ} \mathrm{C}$ then

103 quenched with $7 \mathrm{ml}$ growth medium. The cells were detached by gentle tapping and the cell

104 suspension was centrifuged for 5 minutes at $220 \mathrm{~g}$. The supernatant was discarded and the

105 remaining pellet was re-suspended in an appropriate volume of culture medium. The hMSCs

106 were reseeded at $5 \times 10^{3}$ cells $/ \mathrm{cm}^{2}$ in T-flasks.

107 Cell Separation

108

109 Bone marrow mononuclear cells (BM-MNC) samples, obtained from donors 080004A and

110 071475B with informed consent, were purchased from Lonza (US). Both samples were sorted

111 using manual magnetic-activated cell sorting (MACS) (Miltenyi Biotech, UK) according to

112 the manufacturer's instructions. Briefly, the BM-MNC were incubated with CD271-PE

113 antibody and blocking agent for 10 minutes at $4^{\circ} \mathrm{C}$. Then the samples were washed in buffer,

114 centrifuged and the supernatant aspirated. The samples were then conjugated with anti-PE

115 microbeads for 15 minutes at $4^{\circ} \mathrm{C}$. A LS MACS column was used to isolate both the

$116 \mathrm{CD}_{271^{+\mathrm{ve}}}$ and CD271 ${ }^{-\mathrm{ve}}$ cell fractions which were both plated into separate T-flasks.

\section{Antibody Staining}

119 Detached cells were suspended at $0.5 \times 10^{6}$ cells $/ \mathrm{ml}$ in growth medium and loaded onto a 96

120 well plate $(200 \mu 1$ per well). The plate was centrifuged for 5 minutes at $220 g$. The aspirate was

121 removed and the cells re-suspended and washed in flow cytometry staining buffer (R\&D

122 Systems, UK) and the centrifugation cycle repeated. The cells were stained for 30 minutes in

123 the dark at room temperature with fluorescent monoclonal antibodies against CD34 (PE-

124 CY5), CD73 (PE-Cy7), CD90 (APC), CD105 (PE) and HLA-DR (FITC, all from BD

125 Biosciences, UK) in addition with the corresponding isotype controls. After incubation the 5 
cells were washed twice with staining buffer as before. Finally, $200 \mu 1$ of staining buffer was

127 used to re-suspend the samples before analysis. For CD45/CD271 staining BM-MNC were

128 thawed and dual stained with both CD45 (APC-Cy7, BD Biosciences, UK) and CD271 (PE,

129 Miltenyi Biotec, UK) antibodies using the same protocol as before. The gating strategy was

130 performed in a similar manner to Jones et al, (2010) where the CD271 ${ }^{+\mathrm{ve}} / \mathrm{CD} 45^{-/ \mathrm{low}}$ 131 population was gated.

\section{Flow Cytometry Acquisition and Analysis}

134 All data was obtained using a Guava easyCyte 8HT flow cytometer (Merck Millipore, UK) 135 equipped with $488 \mathrm{~nm}$ and $640 \mathrm{~nm}$ excitation running guavaSoft Incyte acquisition software 136 (v2.5). A minimum of 10,000 gated (Forward scatter/Side scatter) events were recorded for each sample. Compensation values for spectral overlap were determined using anti-mouse Ig, $\kappa$ antibody capture beads as follows (CompBeads, BD Bioscience, UK). A 2 ul suspension of both the positive and negative capture beads was singly stained with each fluorescent

140 antibody as before. For the rest of the protocol CompBeads were treated in the same way as

141 the cells. Post-acquisition analysis and compensation was performed with FlowJo v7.6.5

142 (Treestar Inc, USA) software.

\section{Differentiation}

145 Differentiation was performed using established protocols (Chase et al. 2010). To induce

146 osteogenic differentiation, cells were seeded into a twelve well plate at $5 \times 10^{3}$ cells $/ \mathrm{cm}^{2}$ with

147 Invitrogen StemPro Osteogenesis medium (Invitrogen, UK). The medium was changed every

148 3-4 days. After four weeks in culture, cells were washed and fixed in 4\% (v/v)

149 paraformaldehyde (PFA) for 5 minutes at room temperature. For calcium staining, a solution

150 of $2.5 \%$ silver nitrate (Sigma, UK) was added and cells were incubated for 30 minutes at 151 room temperature under an ultra violet light. Counterstaining for alkaline phosphatase (ALP) 6 
was carried out with a solution containing Fast Violet B Salt with 4\% (v/v) Napthol AS-MX

153 Phosphate Alkaline Solution (Sigma, UK) for 45 minutes at room temperature in the dark.

154 Cells were washed three times in distilled water and visualised under a light microscope

155 (Nikon Eclipse TS-100).

156

157 To induce chondrogenic differentiation, cells were sub-cultured and re-suspended at $1.6 \times 10^{7}$

158 cells $/ \mathrm{ml}$. Micromass cultures were generated by seeding a six well plate with $2 \mu 1$ droplets of

159 cell suspension and allowed to attach to the tissue flask surface in a humidified atmosphere

160 for 30 minutes before adding pre-warmed Invitrogen StemPro Chondrogenesis medium

161 (Invitrogen, UK). The medium was changed every 3-4 days. After 14 days in culture, cells

162 were washed and fixed in $2 \%(\mathrm{v} / \mathrm{v})$ PFA for 30 minutes at room temperature. Chondrocytes

163 were stained with $1 \%(\mathrm{v} / \mathrm{v})$ Alcian Blue in $0.1 \mathrm{M}$ hydrochloric acid $(\mathrm{HCl})$ solution for 30

164 minutes, washed three times with $0.1 \mathrm{M} \mathrm{HCl}$, diluted with distilled water and visualised

165 under a light microscope.

166

167 To induce adipogenic differentiation, cells were seeded in a twelve well plate at $1 \times 10^{4}$ 168 cells $/ \mathrm{cm}^{2}$ with Invitrogen StemPro Adipogenic medium (Invitrogen, UK). The medium was

169 changed every 3-4 days. After three weeks in culture, cells were washed and fixed in 2\%

$170(\mathrm{v} / \mathrm{v})$ PFA for 30 minutes at room temperature. For adipogenic staining, cells were washed

171 three times with PBS and incubated with $0.3 \%(\mathrm{v} / \mathrm{v})$ Oil Red O solution in $99 \%$ isopropanol

172 for 30 minutes at room temperature. Cells were washed three times in distilled water and 173 visualised under a light microscope. 
175 Results and Discussion

176

177

178

179

180

181

182

183

184

185

186

187

188

189

190

191

192

193

194

195

196

197

198

\section{CD271 separation}

Previous work has speculated that CD271 (LNGFR) may be a specific bone marrow hMSC marker (Alvarez-Viejo et al. 2013; Jones et al. 2010). On this basis we performed MACS on two frozen BM-MNC populations using antibodies against CD271 and both resulting cell fractions were plated. After 3 weeks of culture there were no cells found within the CD271 ${ }^{\text {+ve }}$ sorted plates (Fig. 1a), in contrast a large adherent cell population was observed in the $\mathrm{CD} 271^{-\mathrm{ve}}$ plates $\left(\right.$ Fig. 1b). The CD271 ${ }^{\text {-ve }}$ population expressed the CD73, CD90, CD105 ( $\geq 99.9 \%$ in all cases) and did not express CD34 (5.37\%) and HLA-DR (5.14\%) (Fig. 1c).

Previous reports have demonstrated a rare population of $\mathrm{CD} 271^{+\mathrm{ve}} / \mathrm{CD} 45^{-/ \mathrm{low}}$ cells found in bone marrow aspirates (Jones et al. 2010). Therefore we performed dual-staining flow cytometry for CD45/CD271 on the BM-MNCs. The gating strategy used to analyse the population was performed in a similar manner to previously published reports (Cox et al. 2012; Jones et al. 2006). Similarly to the MACS technique we could not detect a significant number of $\mathrm{CD} 271^{+\mathrm{ve}}$ cells $(0.16 \% \pm 0.02 \%)$ or the presence of a discrete population in the $\mathrm{CD} 271^{+\mathrm{ve}} / \mathrm{CD} 45^{-/ \mathrm{low}}$ gate (Fig. 1d).

These findings are supported by the comprehensive proteomic profiling conducted by the US Food and Drug Administration (FDA) which only found CD271 expression in one out of four donor samples (Mindaye et al. 2013). This variability of CD271 expression has also been reported by other groups (Alvarez-Viejo et al. 2013; Siegel et al. 2013). 
201 To validate the panel of markers for the multiparameter study the hMSC samples were first 202 labelled with single antibodies against the markers of interest (Fig. 2). The ISCT suggests $203 \geq 95 \%$ purity for expression of positive markers. Through this method, single staining results 204 showed a highly enriched sample of the three positive markers CD73, CD90 and CD105 205 (100\%). Additionally they demonstrated little expression of the negative markers CD34 and HLA-DR $(<3.5 \%$ in both cases). Due to this being outside of the ISCT range for negative markers $(\leq 2 \%)$ we then sought to develop a multiparameter approach to find the true expression of $\mathrm{CD} 73^{+\mathrm{ve}} / \mathrm{CD} 105^{+\mathrm{ve}} / \mathrm{CD} 90^{+\mathrm{ve}} / \mathrm{HLA}^{-\mathrm{DR}} \mathrm{Re}^{-\mathrm{ve}} / \mathrm{CD} 34^{-\mathrm{ve}}$ in the population.

Multiparameter Flow Cytometry

212 Many publications regarding hMSC characterisation via flow cytometry employ either single 213 or double stained populations. Although these techniques validate the expression of surface

214 markers they do not give a representation of the population when taken together. Therefore

215 the population was next examined using the multiparameter approach. All dual analyses of 216 the different combinations of CD73, CD90 and CD105 showed a $>99 \%$ positive population

217 similar to the previous single colour analyses. In all cases $>90 \%$ of the population fell within 218 the HLA-DR ${ }^{-v e} / \mathrm{CD} 34^{-\mathrm{ve}}$ gate with the overall average at 95\% (Fig. 3). Taken together, these 219 plots show that the population is a highly pure sample of hMSCs with most cells expressing 220 the correct positive markers and lacking the selected negative markers.

222 Serial gating was then performed to further analyse the hMSC population (Fig. 4). From the 223 initial starting populations, defined from the forward and side scatter, each marker 224 combination was examined in turn until a full cell surface marker phenotype was established. 9 
225 The $\mathrm{CD} 73^{+\mathrm{ve}} / \mathrm{CD} 105^{+\mathrm{ve}}$ population was first gated, and as with the dual analysis over $99 \%$ of 226 the population expressed this combination. This quadrant was then analysed for CD90 and

227 HLA-DR. As expected, the cell population fell within the CD90 ${ }^{+v e} / H_{L A}-D^{-v e}$ quadrant. 228 Finally the resulting cells were gated for CD34 and HLA-DR. As seen previously in Fig 2, 229 the population was found in the HLA-DR ${ }^{-\mathrm{ve}} / \mathrm{CD} 34^{-\mathrm{ve}}$ quadrant. From this the number of cells 230 with the surface marker expression to be $\mathrm{CD} 73^{+\mathrm{ve}} / \mathrm{CD} 105^{+\mathrm{ve}} / \mathrm{CD} 90^{+\mathrm{ve}} / \mathrm{HLA}-\mathrm{DR} \mathrm{R}^{-\mathrm{ve}} / \mathrm{CD} 34^{-\mathrm{ve}}$ 231 was calculated to be $94.49 \% \pm 1.31 \%$ of the original gated population (Table 1.). This is 232 lower when compared to results from the single staining where the population was considered 233 to be $100 \%$ positive for a mesenchymal phenotype indicating multiparameter analysis with 234 serial gating allows for a more stringent analysis and indicates the purity of the hMSC population.

237 Throughout this study the cell surface markers were chosen based upon the ISCT 238 recommendations (Dominici et al. 2006). CD73, CD90 and CD105 are all expressed on 239 hMSCs even through extended culture, making them an ideal combination for cell 240 identification (Bernardo et al. 2007). CD105, also known as endoglin, is a receptor for TGF$241 \beta_{1}$. It is known that these receptors are mediators of cell proliferation and differentiation down the osteoblast and chondrocyte lineages whilst inhibiting the adipogenic lineage 243 (Roelen and Dijke 2003). Upon differentiation down these lineages CD105 is down regulated 244 making it a valuable marker of cell multipotency (Jin et al. 2009).

246 Human MSCs are costly to isolate and culture, so by taking a multiparameter approach the

247 phenotype analysis requires fewer cells and reagents, as well as reduced operator time 248 representing a real cost saving for laboratories. For the multicolour assay fewer samples of 249 cells than the usual single staining were prepared, one 5-isotype control, one unstained tube 10 
and four multicolour test samples with an additional six wells for the compensation beads. In contrast the conventional single staining method would require at least twice this number to achieve a less stringent characterisation. This is important for autologous cell therapies, especially for older patients, where cell quantity may be limited and fewer cells are available

254 for analysis.

\section{Differentiation}

To demonstrate multipotency of the hMSCs differentiation into chondrocytes, adipocytes and osteoblasts was performed using well-established techniques. To induce chondrogenic differentiation the cells were plated as micromass cultures onto tissue culture plastic with

261 chondrogenic differentiation media. Positive Alcian Blue staining demonstrates the

262 deposition of sulphated proteoglycans, typically secreted by chondrocytes into the extracellular matrix (Fig. 5a). After 14 days of adipogenic differentiation, treated hMSCs accumulated lipid vacuoles that are characteristic of adipocytes. The presence of lipid vacuoles was confirmed via Oil Red O staining (Fig. 5b). No lipid vacuoles were seen in the control samples. Finally, the osteogenic differentiation potential of the hMSCs was demonstrated following 21 days of culture in differentiation media. The treated cells showed alkaline phosphatase activity as seen by Fast Violet B Salt with 4\% (v/v) Napthol AS-MX Phosphate Alkaline staining (red) and calcium deposition (black) (Fig. 5c).

By demonstrating the ability for trilineage differentiation into adipocytes, chondrocytes and osteoblasts as well as adherence to tissue culture plastic this fulfils the criteria outlined by the ISCT for the maintenance of hMSC phenotype. 


\section{Conclusion}

276 The aim of this study was to develop a multiparameter flow cytometry assay to analyse

277 hMSCs at the single-cell level. Fresh bone marrow aspirates are a heterogeneous population

278 containing several subpopulations of distinct cell types from which the hMSCs are isolated. A

279 major obstacle for characterisation is that to date there is no single marker that defines an

280 hMSC. As such, researchers use a panel of indicators to measure population purity creating a

281 need for these multiparameter approaches.

282

283 Multiparameter flow cytometry provides a way to determine cell phenotype based on surface proteins in a way that goes beyond the current single colour methodologies. With this method we were able to identify a population of hMSCs that express the cell surface marker panel as suggested by the ISCT. Our multiparameter assay gives a stringent analysis of the population, as each cell must pass through three separate gating strategies to be considered a fully

288 functional hMSC. Our results show that the triple gated population was $94.49 \% \pm 1.31 \%$ for the $\mathrm{CD} 73^{+\mathrm{ve}} / \mathrm{CD} 105^{+\mathrm{ve}} / \mathrm{CD} 90^{+\mathrm{ve}} / \mathrm{HLA}-\mathrm{DR}^{-\mathrm{ve}} / \mathrm{CD} 34^{-\mathrm{ve}}$ expression phenotype, compared to what was considered to be $100 \%$ pure via the single staining approach. Even though this is just under the threshold value set by the ISCT we believe single stain analysis will give an overestimation of the purity of the population whereas the multiparameter method allows for full single-cell phenotype analysis thus a more stringent cell classification.

295 Studies have suggested CD271 to be a specific marker for early passage bone-marrow hMSCs. Our findings from the flow cytometry study and MACS conducted here have

297 indicated there is little to no expression of this marker in the cells studied here. Given the low 298 abundance of this specific antigen and the need for a large number of cells for therapeutic use 
299 it is concluded that CD271 may not be an appropriate marker choice on which to base the

300 isolation of hMSCs.

301

302 Whilst multiparameter flow cytometry within the stem cell community is still not widely

303 performed recent reports suggest that this technique will become increasingly

304 important(Zimmerlin et al. 2010; Zimmerlin et al. 2012; Khalili et al. 2012). This is attributed

305 to a growing demand to measure multiple parameters in a single sample, thus maximising the

306 information gathered and enhancing the depth of collected data.

307

308 Acknowledgments

309 The authors acknowledge funding support from the Engineering and Physical Sciences

310 Research Council (EPSRC) Doctoral Training Centre in Regenerative Medicine and

311 Bioprocessing Research Industries Club (BRIC). The authors would also like to thank

312 Andrew Want, Merck Millipore UK, for his training and input to the study design. 


\section{References}

314 Alvarez-Viejo M, Menendez-Menendez Y, Blanco-Gelaz MA, Ferrero-Gutierrez A, Fernandez-Rodriguez MA, Gala J, Otero-Hernandez J (2013) Quantifying mesenchymal stem cells in the mononuclear cell fraction of bone marrow samples obtained for cell therapy. Transplant Proc 45:434-439.

317 Bernardo ME, Zaffaroni N, Novara F, Cometa AM, Avanzini MA, Moretta A, Montagna D, Maccario R, Villa R, Daidone MG, Zuffardi O, Locatelli F (2007) Human bone marrow derived mesenchymal stem cells do not undergo transformation after long-term in vitro culture and do not exhibit telomere maintenance mechanisms. Cancer Res 67:9142-9149.

Brosnan K, Want A, Coopman K, Hewitt CJ (2013) Multiparameter flow cytometry for the characterization of human embryonic stem cells. Biotechnol Lett 35:55-65.

Caplan AI (2007) Adult mesenchymal stem cells for tissue engineering versus regenerative medicine. J Cell Physiol 213:341-347.

Chase LG, Lakshmipathy U, Solchaga LA, Rao MS, Vemuri MC (2010) A novel serum-free medium for the expansion of human mesenchymal stem cells. Stem cell research \& therapy 1:8.

Cox G, Boxall SA, Giannoudis PV, Buckley CT, Roshdy T, Churchman SM, McGonagle D, Jones E (2012) High abundance of CD271(+) multipotential stromal cells (MSCs) in intramedullary cavities of long bones. Bone 50:510-517.

Dominici M, Le Blanc K, Mueller I, Slaper-Cortenbach I, Marini F, Krause D, Deans R, Keating A, Prockop D, Horwitz E (2006) Minimal criteria for defining multipotent mesenchymal stromal cells. The International Society for Cellular Therapy position statement. Cytotherapy 8:315-317.

Friedenstein AJ, Chailakhjan RK, Lalykina KS (1970) The development of fibroblast colonies in monolayer cultures of guinea-pig bone marrow and spleen cells. Cell Tissue Kinet 3:393-403.

Harichandan A, Buhring HJ (2011) Prospective isolation of human MSC. Best Pract Res Clin Haematol 24:2536.

Jin HJ, Park SK, Oh W, Yang YS, Kim SW, Choi SJ (2009) Down-regulation of CD105 is associated with

Jones E, English A, Churchman SM, Kouroupis D, Boxall SA, Kinsey S, Giannoudis PG, Emery P, McGonagle D (2010) Large-scale extraction and characterization of CD271+ multipotential stromal cells from 
trabecular bone in health and osteoarthritis: implications for bone regeneration strategies based on uncultured or minimally cultured multipotential stromal cells. Arthritis Rheum 62:1944-1954.

344 Jones EA, English A, Kinsey SE, Straszynski L, Emery P, Ponchel F, McGonagle D (2006) Optimization of a flow cytometry-based protocol for detection and phenotypic characterization of multipotent mesenchymal stromal cells from human bone marrow. Cytometry B Clin Cytom 70:391-399.

Khalili S, Liu Y, Kornete M, Roescher N, Kodama S, Peterson A, Piccirillo CA, Tran SD (2012) Mesenchymal stromal cells improve salivary function and reduce lymphocytic infiltrates in mice with Sjogren's-like disease. PLoS One 7:e38615.

Kuci S, Kuci Z, Kreyenberg H, Deak E, Putsch K, Huenecke S, Amara C, Koller S, Rettinger E, Grez M, Koehl U, Latifi-Pupovci H, Henschler R, Tonn T, von Laer D, Klingebiel T, Bader P (2010) CD271 antigen defines a subset of multipotent stromal cells with immunosuppressive and lymphohematopoietic engraftment-promoting properties. Haematologica 95:651-659.

Martins AA, Paiva A, Morgado JM, Gomes A, Pais ML (2009) Quantification and immunophenotypic characterization of bone marrow and umbilical cord blood mesenchymal stem cells by multicolor flow cytometry. Transplant Proc 41:943-946.

Mindaye ST, Ra M, Lo Surdo J, Bauer SR, Alterman MA (2013) Improved proteomic profiling of the cell surface of culture-expanded human bone marrow multipotent stromal cells. J Proteomics 78:1-14.

Peters JM, Ansari MQ (2011) Multiparameter flow cytometry in the diagnosis and management of acute leukemia. Arch Pathol Lab Med 135:44-54.

Pittenger MF, Mackay AM, Beck SC, Jaiswal RK, Douglas R, Mosca JD, Moorman MA, Simonetti DW, Craig S, Marshak DR (1999) Multilineage potential of adult human mesenchymal stem cells. Science 284:143-147.

Rasini V, Dominici M, Kluba T, Siegel G, Lusenti G, Northoff H, Horwitz EM, Schafer R (2013) Mesenchymal stromal/stem cells markers in the human bone marrow. Cytotherapy 15:292-306.

Roelen BA, Dijke P (2003) Controlling mesenchymal stem cell differentiation by TGFBeta family members. J Orthop Sci 8:740-748.

Rojewski MT, Weber BM, Schrezenmeier H (2008) Phenotypic Characterization of Mesenchymal Stem Cells from Various Tissues. Transfus Med Hemother 35:168-184.

Siegel G, Kluba T, Hermanutz-Klein U, Bieback K, Northoff H, Schafer R (2013) Phenotype, donor age and gender affect function of human bone marrow-derived mesenchymal stromal cells. BMC Med 11:146. 
Williams AR, Hare JM (2011) Mesenchymal stem cells: biology, pathophysiology, translational findings, and therapeutic implications for cardiac disease. Circ Res 109:923-940.

Zimmerlin L, Donnenberg VS, Pfeifer ME, Meyer EM, Peault B, Rubin JP, Donnenberg AD (2010) Stromal vascular progenitors in adult human adipose tissue. Cytometry A 77:22-30.

Zimmerlin L, Donnenberg VS, Rubin JP, Donnenberg AD (2012) Mesenchymal markers on human adipose stem/progenitor cells. Cytometry A.

Table 1. The samples were initially gated on the single cell population followed by DR/CD34 respectively to assess, from the starting population, the percent of cells with the $\mathrm{CD} 105^{+\mathrm{ve}} / \mathrm{CD} 73^{+\mathrm{ve}} / \mathrm{CD} 90^{+\mathrm{ve}} / \mathrm{HLA}_{-\mathrm{DR}}{ }^{-\mathrm{ve}} / \mathrm{CD} 34^{-\mathrm{ve}}$ phenotype. \pm values represent the $\mathrm{SE}, n \geq 3$

383 in all cases.

Figure 1. CD271 separation and analysis of bone marrow mononuclear cells. (a) Image of tissue culture flask 21 days following CD271 ${ }^{+v e}$ MACs separation population showing no cells. (b) CD271 ${ }^{-v e}$ fraction shows appearance of adherent stromal cells. Scale bar $=250 \mu \mathrm{m}$. (c) Flow cytometry analysis of hMSCs obtained from the CD271 ${ }^{\text {-ve }}$ fraction shows expression of CD73, CD90 and CD105 whilst lacking CD34 and HLA-DR. (d) Dual staining for CD271/CD45 shows an insignificant number of CD271 $1^{+v e}$ cells, $0.16 \% \pm 0.02 \%(n=3)$.

392 Figure 2. Single colour flow cytometry results for expression of selected markers of hMSCs

393 (filled). Isotype gating (outline) was set to 95\%. Positive markers CD73 (PE-Cy5), CD90

394 (APC), CD105 (PE) compared to negative markers CD34 (PE-Cy7) and HLA-DR (FITC).

395 Graphs are representative of 4 separate experiments. 
397 Figure 3. Five colour analysis of a single population of hMSCs. The cell surface markers 398 CD73, CD90 and CD105 show $>99 \%$ positive expression. Negative markers, CD34 and 399 HLA-DR, were found in the negative quadrant. Isotype gating was set to $95 \%$. Each dot plot 400 is accompanied by bar charts that represent each quadrant showing the mean of the samples 401 (error bars indicate the SE). $n \geq 3$ in all cases.

402

403 Figure 4. Serial gating of hMSCs showing co-expression of the surface markers. The initial 404 analysis region used forward and side scatter to determine the population of interest. This was then gated for the $\mathrm{CD} 73^{+\mathrm{ve}}$ and $\mathrm{CD} 105^{+\mathrm{ve}}$ cells. Sequential gating was used to determine the $406 \mathrm{CD}^{+\mathrm{ve}} / \mathrm{HLA}^{-\mathrm{DR}^{-\mathrm{ve}}}$ and the HLA-DR ${ }^{-\mathrm{ve}} / \mathrm{CD}^{-\mathrm{ve}} 4^{-\mathrm{p}}$ population. From the initial gate $95 \%$ of 407 cells had the $\mathrm{CD} 73^{+\mathrm{ve}} / \mathrm{CD} 105^{+\mathrm{ve}} / \mathrm{CD} 90^{+\mathrm{ve}} / \mathrm{HLA}-\mathrm{DR}^{-\mathrm{ve}} / \mathrm{CD} 34^{-\mathrm{ve}}$ cell surface expression 408 phenotype.

411 Figure 5. Histology of differentiated mesenchymal stem cells to demonstrate multilineage 412 potential. (a) Phase-contrast microscopy of micromass cultures differentiated down the 413 chondrocyte lineage. The cells were fixed and stained with Alcian Blue. (b) Microscopy of 414 cells following 14 days of adipogenic differentiation. The samples were fixed and stained 415 with Oil Red O. (c) Phase-contrast microscopy of cells following 21 days of osteogenic 416 differentiation. Following fixation the samples were stained using Fast Violet B Salt with 4\% 417 (v/v) Napthol AS-MX Phosphate Alkaline Solution. Magnification 10x. Scale bar $=250 \mu \mathrm{m}$. 
(a)

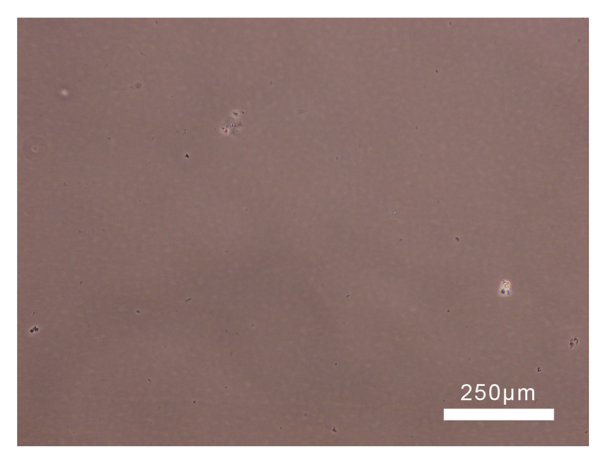

(c)
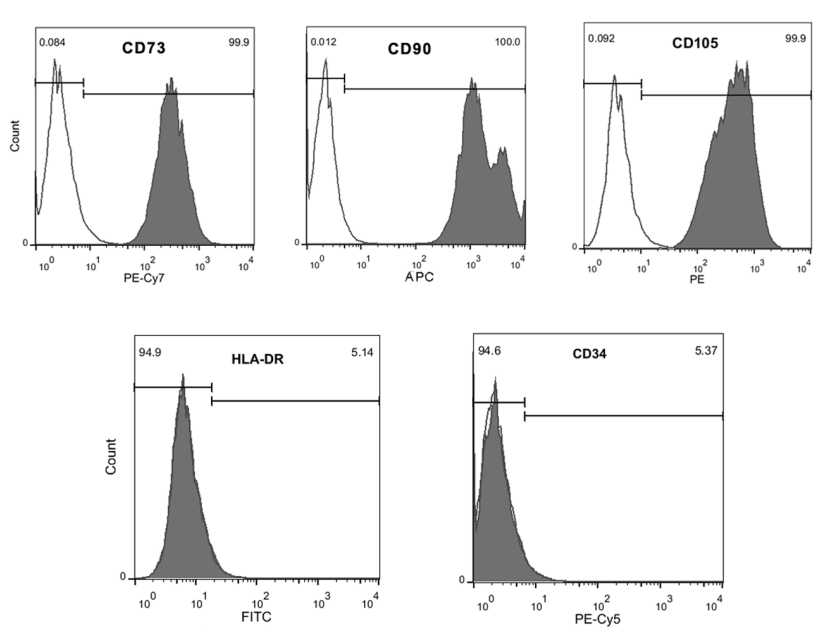

420
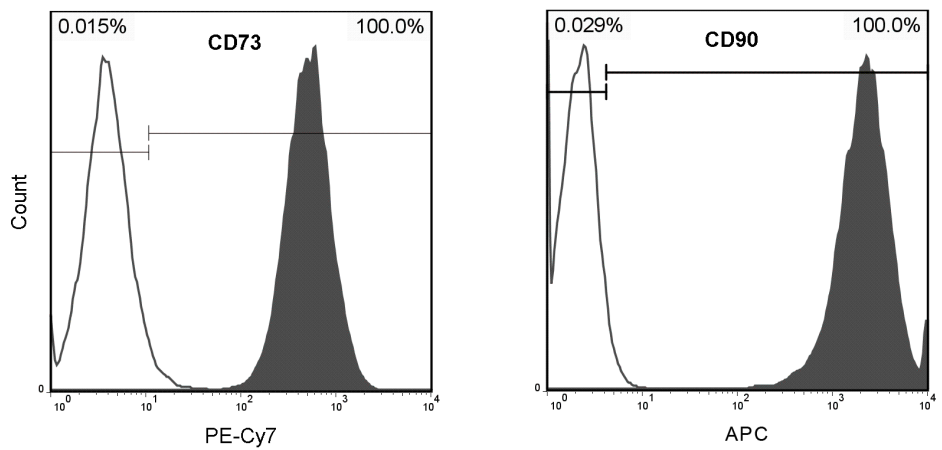

(d)
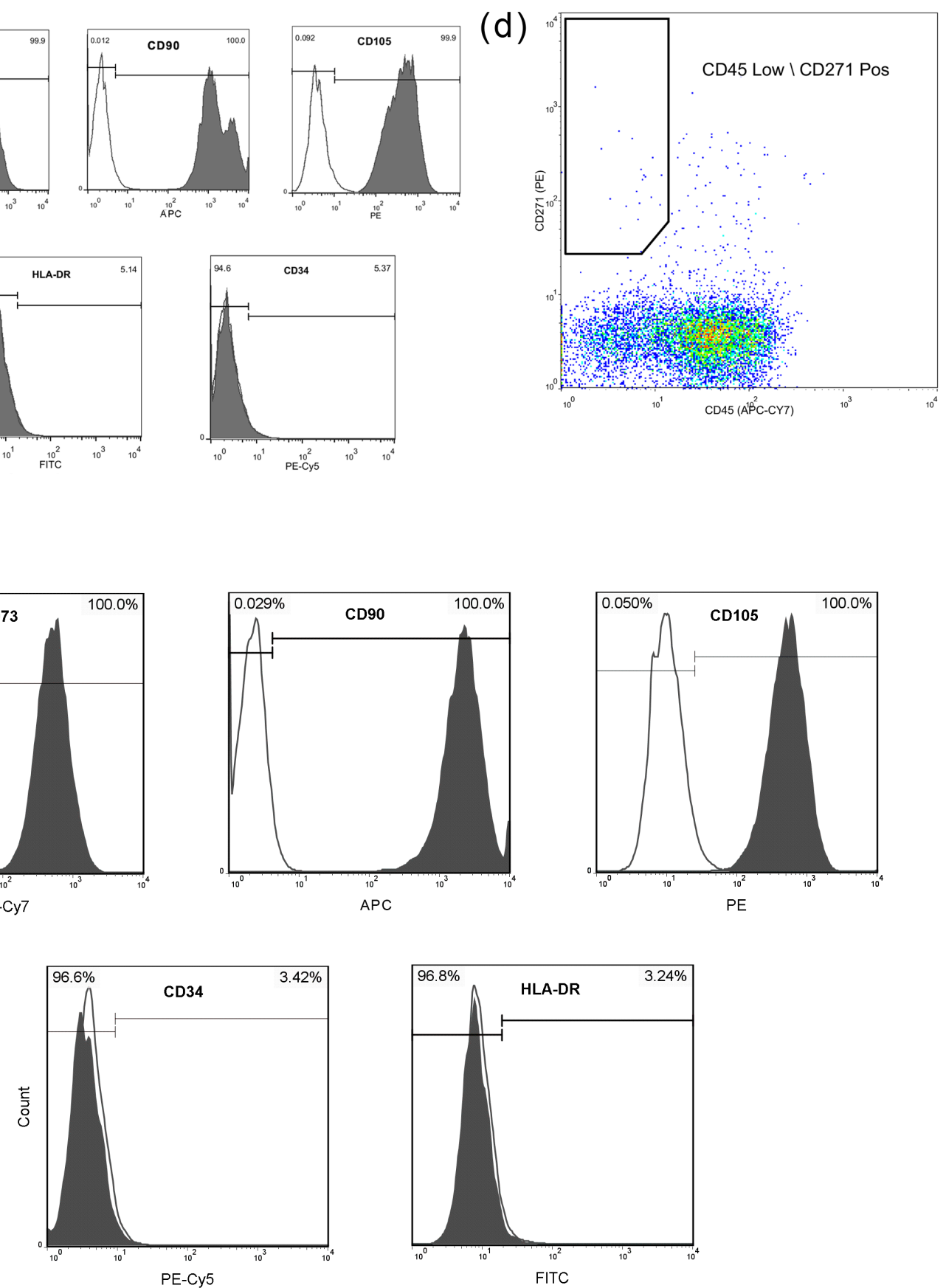

421

PE-Cy5

FITC 

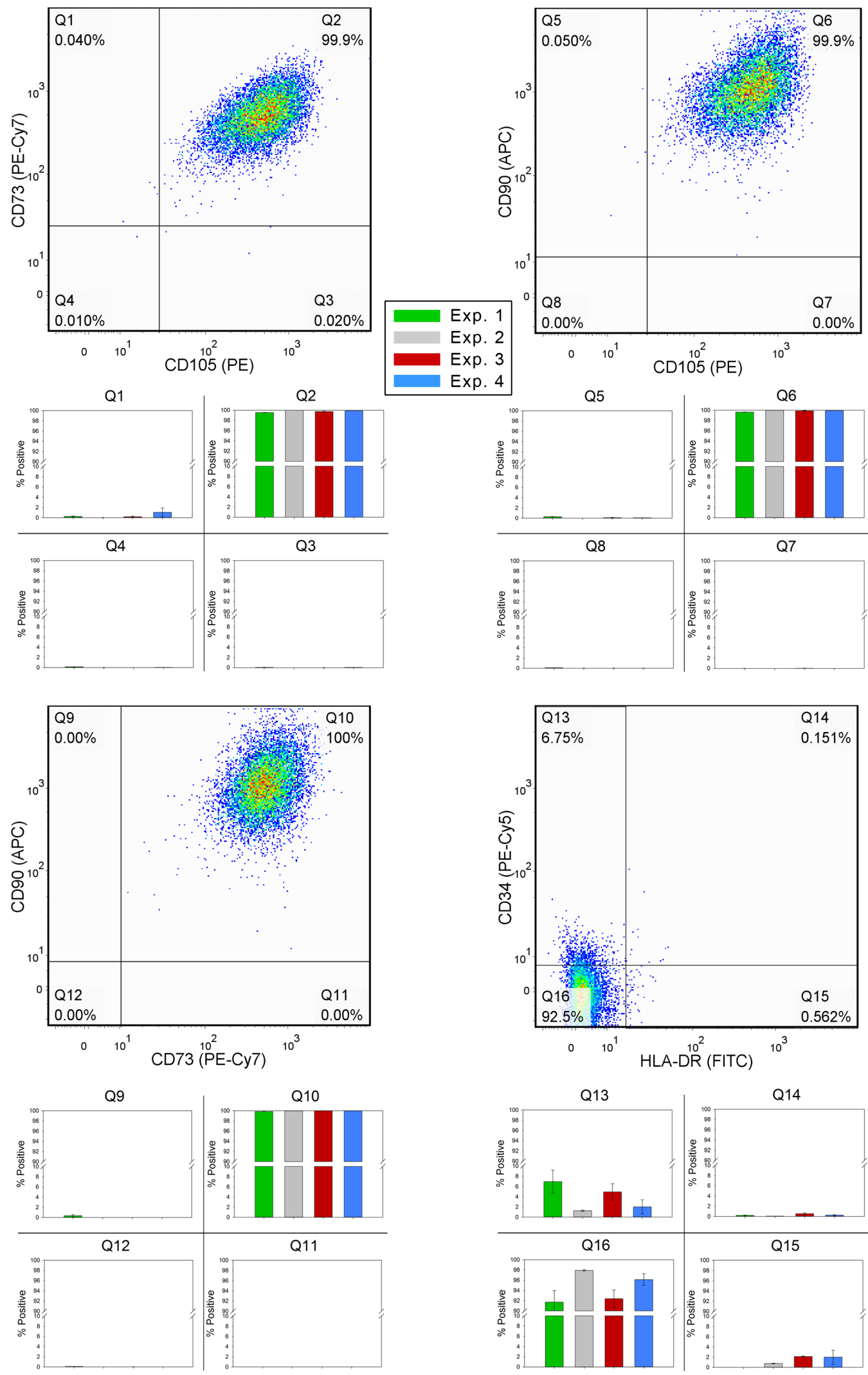

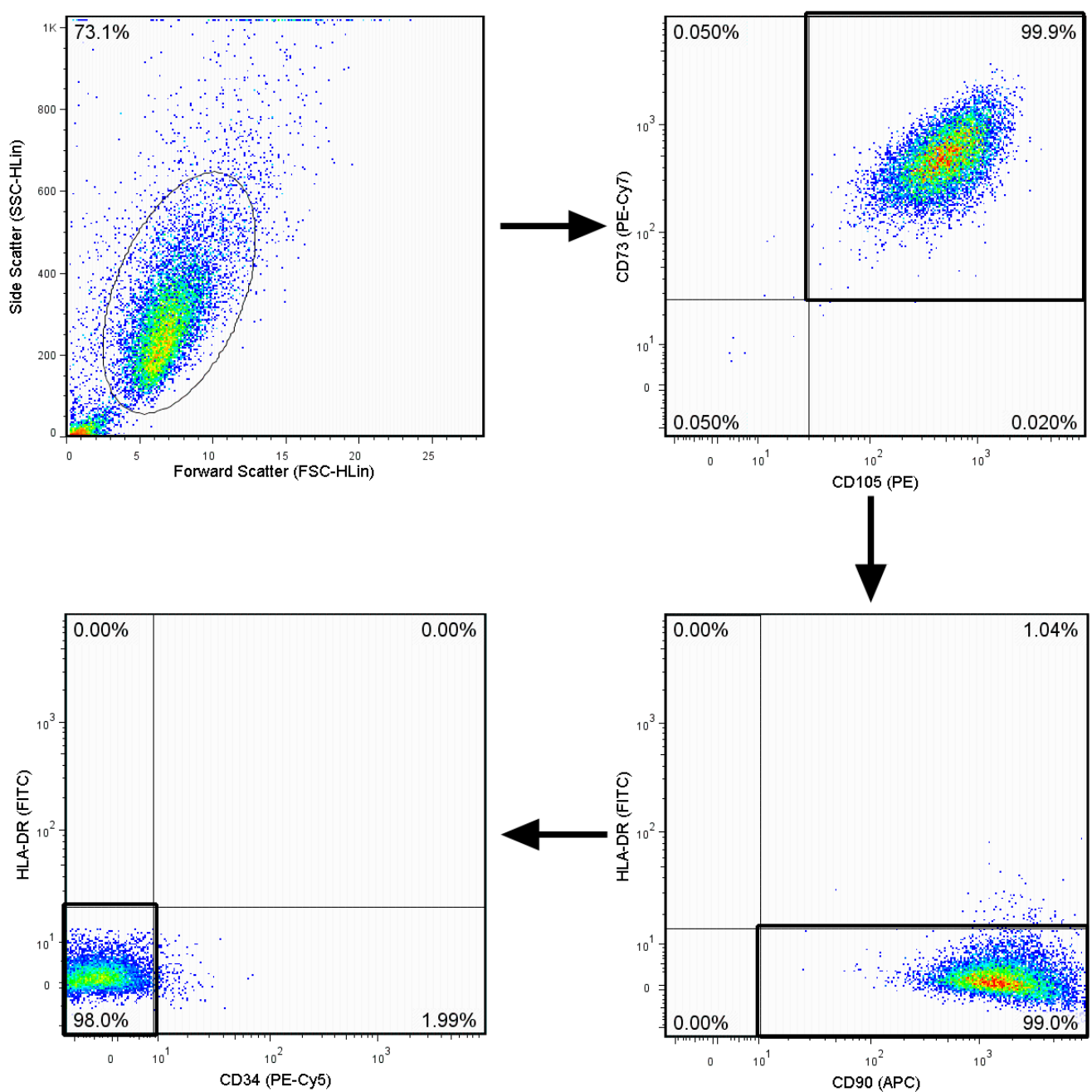

424

(a)

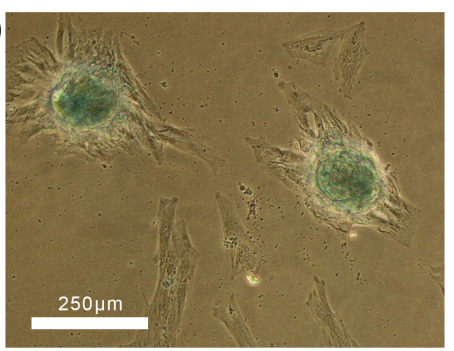

(b)

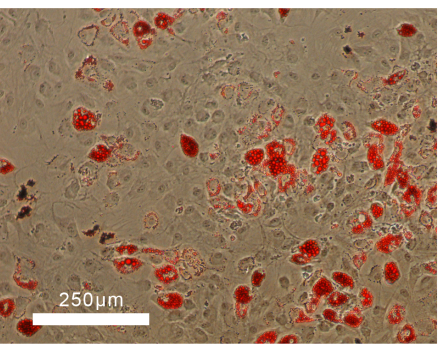

(c)

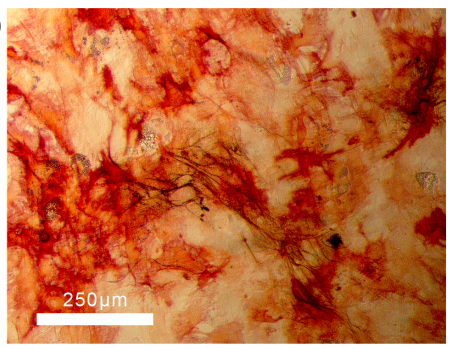

425

426 
$\%$ Expression from Multiparameter Data

\begin{tabular}{|c|c|c|c|c|c|c|c|c|c|c|c|}
\hline & & \multicolumn{2}{|c|}{ Subset 1: CD105 / CD73 } & $\rightarrow$ & \multicolumn{2}{|c|}{ Subset 2: HLA-DR / CD90 } & $\rightarrow$ & \multicolumn{2}{|c|}{ Subset 3: HLA-DR / CD34 } & \multirow{2}{*}{\multicolumn{2}{|c|}{$\begin{array}{l}\% \quad \text { with } \\
\text { phenotype }\end{array}$}} \\
\hline \multirow{4}{*}{$\begin{array}{l}\operatorname{Exp} \\
(n=3)\end{array}$} & \multirow{4}{*}{1} & CD105- / CD73+ & $0.24 \pm 0.06$ & \multirow{4}{*}{$\rightarrow$} & HLA-DR- / CD90+ & $98.80 \pm 0.05$ & $\rightarrow$ & HLA-DR- / CD34+ & $7.06 \pm 2.31$ & & \\
\hline & & $\mathrm{CD} 105+/ \mathrm{CD} 73+$ & $99.53 \pm 0.03$ & & HLA-DR+ / CD90+ & $1.22 \pm 0.05$ & & HLA-DR+ / CD34+ & $0.00 \pm 0.00$ & \multirow[t]{3}{*}{$91.32 \pm 2.04 \%$} & \\
\hline & & CD105+ / CD73- & $0.06 \pm 0.02$ & & HLA-DR+ / CD90- & $0.00 \pm 0.00$ & & HLA-DR+ / CD34- & $0.05 \pm 0.02$ & & \\
\hline & & CD105- / CD73- & $0.16 \pm 0.02$ & & HLA-DR- / CD90- & $0.00 \pm 0.00$ & & HLA-DR- / CD34- & $92.87 \pm 2.28$ & & \\
\hline \multirow{5}{*}{$\begin{array}{l}\operatorname{Exp} \\
(n=4)\end{array}$} & \multirow{4}{*}{2} & CD105- / CD73+ & $0.00 \pm 0.00$ & \multirow{4}{*}{$\rightarrow$} & HLA-DR- / CD90+ & $99.37 \pm 0.06$ & \multirow{4}{*}{$\rightarrow$} & HLA-DR- / CD34+ & $1.14 \pm 0.03$ & \multirow{4}{*}{$98 \pm 0.09 \%$} & \\
\hline & & CD105+ / CD73+ & $100.00 \pm 0.00$ & & HLA-DR+ / CD90+ & $0.61 \pm 0.05$ & & HLA-DR+ / CD34+ & $0.01 \pm 0.00$ & & \\
\hline & & CD105+ / CD73- & $0.00 \pm 0.00$ & & HLA-DR+ / CD90- & $0.00 \pm 0.00$ & & HLA-DR+ / CD34- & $0.19 \pm 0.03$ & & \\
\hline & & CD105- / CD73- & $0.02 \pm 0.01$ & & HLA-DR- / CD90- & $0.00 \pm 0.00$ & & HLA-DR- / CD34- & $98.63 \pm 0.02$ & & \\
\hline & & CD105- / CD73+ & $0.01 \pm 0.00$ & \multirow{4}{*}{$\rightarrow$} & HLA-DR- / CD90+ & $97.37 \pm 0.12$ & $\rightarrow$ & HLA-DR- / CD34+ & $5.46 \pm 2.20$ & \multirow{4}{*}{$91.90 \pm 2.40 \%$} & \\
\hline \multirow{3}{*}{$\begin{array}{l}\operatorname{Exp} \\
(n=4)\end{array}$} & 3 & CD105+ / CD73+ & $99.80 \pm 0.16$ & & HLA-DR + / CD90+ & $2.60 \pm 0.13$ & & HLA-DR + / CD34+ & $0.00 \pm 0.00$ & & \\
\hline & & CD105+/ CD73- & $0.21 \pm 0.14$ & & HLA-DR+ / CD90- & $0.00 \pm 0.00$ & & HLA-DR+ / CD34- & $0.00 \pm 0.00$ & & \\
\hline & & CD105- / CD73- & $0.01 \pm 0.01$ & & HLA-DR- / CD90- & $0.02 \pm 0.01$ & & HLA-DR- / CD34- & $94.57 \pm 2.20$ & & \\
\hline
\end{tabular}




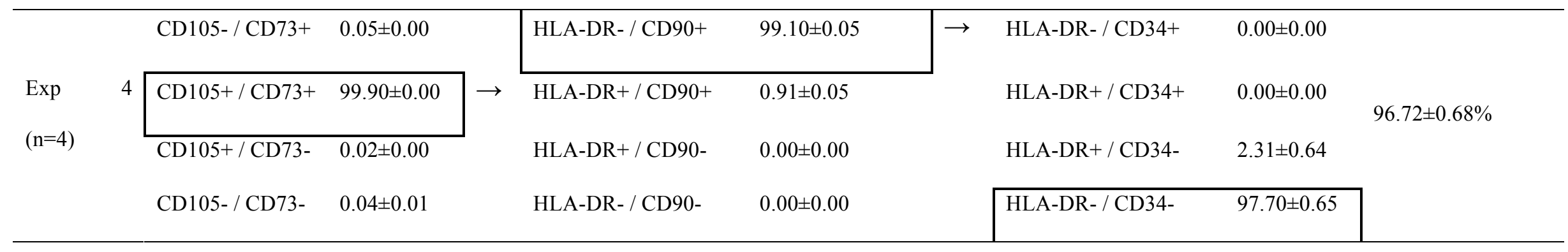

427 